\title{
February 2016 Pulmonary Case of the Month
}

\author{
Ashley Garrett, MD \\ Karen Swanson, DO \\ Pulmonary Department \\ Mayo Clinic Arizona \\ Scottsdale, AZ USA
}

\section{History of Present IIIness}

A 77-year-old woman presented with dyspnea on exertion which was progressive for several years. She remains active but is "winded" with vigorous exercise or altitude. She denied cough, orthopnea, paroxysmal nocturnal dyspnea, chest pain or a prior history of pulmonary infections.

\section{Past Medical, Social and Family History}

She has a history of a seizure disorder and fibromyalgia. She has never smoked or drank and has no history of occupational exposures. There was no family history of respiratory disease.

\section{Physical Examination}

Her physical exam was unremarkable.

\section{Current Medications}

Topamax and alprazolam.

\section{Radiography}

A chest radiograph was performed (Figure 1).

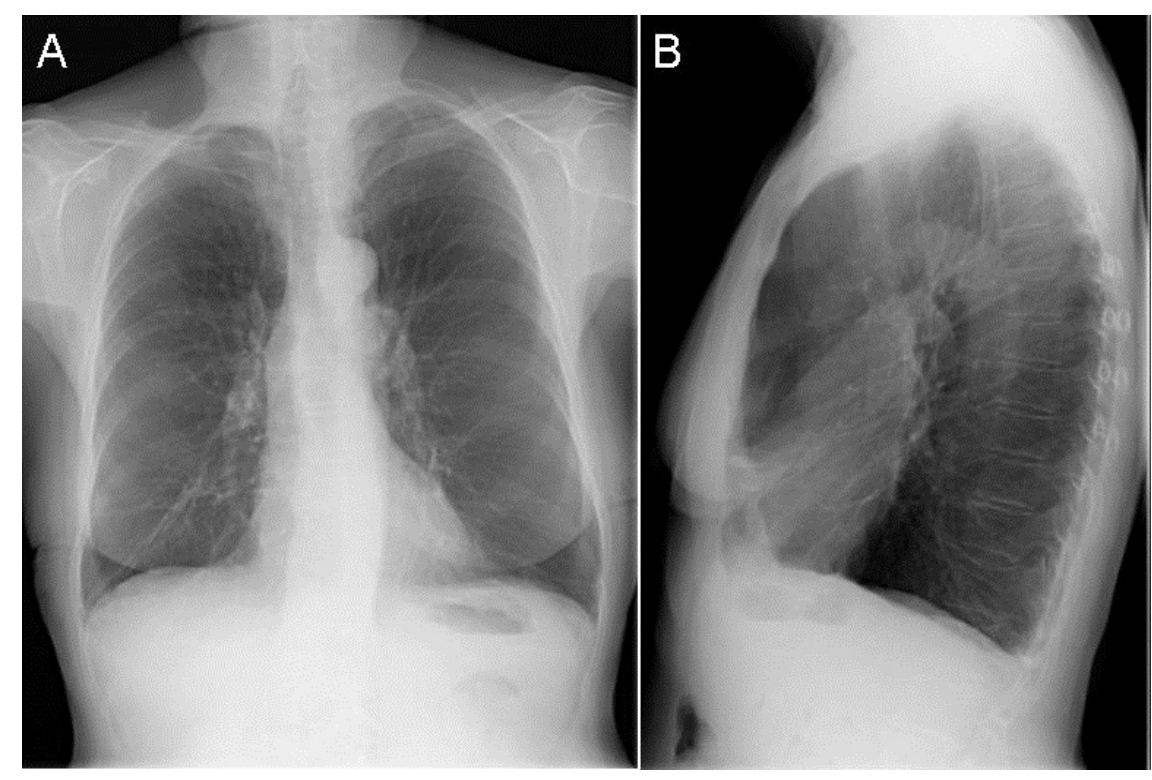

Figure 1. Initial chest radiography. 
Which of the following describe the initial chest x-ray?

1. The chest $x$-ray is normal

2. There is a left lower mass

3. There is bronchial dilatation and edema

4. There is hyperinflation

5. Three is a retrocardiac left lower pneumonia 


\section{Correct! \\ 4. There is hyperinflation}

There is flattening of the diaphragms. The normal dome of each hemidiaphragm should rise at least $1.5 \mathrm{~cm}$ above a line connecting the costophrenic angle posteriorly and sternophrenic angle anteriorly. There is also widening of the retrosternal airspace which should be less than $2.5 \mathrm{~cm}$. Both these findings are consistent with hyperinflation. There are no masses, consolidation or visible bronchi.

Which of the following should be done next?

1. CT scan of the chest

2. Flexible fiberoptic bronchoscopy with bronchoalveolar lavage

3. Pulmonary function testing

4. 1 and 3

5. All of the above 


\section{Correct!}

\section{1 and 3}

Her dyspnea appears to be related to a pulmonary problem. Therefore, pulmonary function testing is indicated. Her pulmonary function tests are shown in Figure 2.

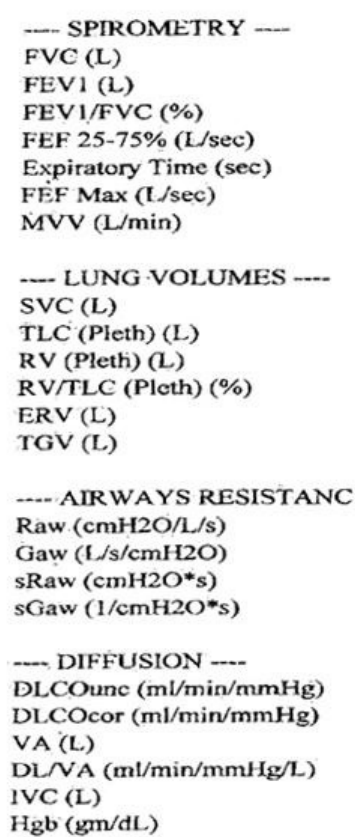

Pre-Bronch Pred Actual \%Pred

Post-Bronch

$\begin{array}{rrrrrr}2.48 & 2.62 & 105 & 2.79 & 112 & +6 \\ 1.85 & * 1.04 & * 55 & * 1.12 & * 60 & +8 \\ 74 & * 39 & * 53 & * 40 & * 54 & + \\ 1.44 & 0.28 & 19 & 0.35 & 24 & +24 \\ & 15.20 & & 14.73 & & -3 \\ 4.75 & * 3.09 & * 64 & 3.23 & 68 & +4 \\ 78 & * 46 & * 58 & & & \end{array}$

$\begin{array}{rrr}2.48 & 2.57 & 103 \\ 4.33 & 6.41 & 148 \\ 1.83 & * 3.84 & * 209 \\ 42 & * 60 & * 142 \\ 0.68 & 0.71 & 104 \\ 2.53 & * 4.55 & * 179\end{array}$

$\begin{array}{lll}1.86 & 1.35 & 72\end{array}$

$\begin{array}{lll}1.03 & 0.75 & 73\end{array}$

$<4.76$

$\begin{array}{lll}0.20 & 0.15 & 73\end{array}$

$\begin{array}{lll}18.90 & * 9.30 & * 49 \\ 18.90 & * 9.24 & * 48\end{array}$

$\begin{array}{lll}4.73 & 4: 20 \quad 88\end{array}$

$4.27+2.20$

2.32
$12-18 \quad 13.6$

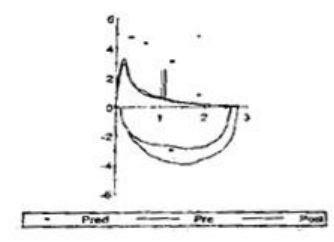

al $\%$ Pred \%Chng

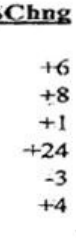

Figure 2. Complete pulmonary function testing. The flow-volume loop is shown on the right.

There was a question of pulmonary embolism and a thoracic CT scan was performed (Figure 3).

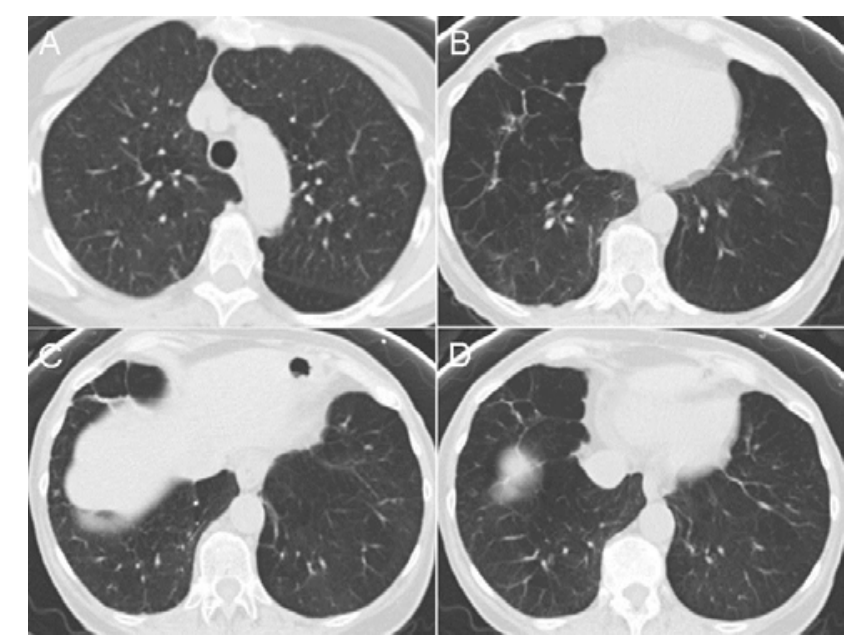

Figure 3. Selected images in lung windows from the thoracic CT scan. 
Which of the following are true regarding the pulmonary function testing and thoracic CT scan?

1. The pulmonary function testing and CT scan are normal

2. The pulmonary function testing shows mixed obstruction and restriction and there are small nodules on the CT scan

3. The pulmonary function testing shows nonreversible airway obstruction and the CT scan shows decreased vascular markings consistent with emphysema

4. The pulmonary function testing shows restrictive lung disease and the CT scan shows honeycombing consistent with pulmonary fibrosis

5. The pulmonary function testing shows reversible airway obstruction and the CT scan shows hyperinflation consistent with asthma 


\section{Correct!}

3. The pulmonary function testing shows nonreversible airway obstruction and the CT scan shows decreased vascular markings consistent with emphysema

There is a reduction in the forced expiratory volume in 1 second (FEV1) with a normal forced vital capacity (FVC). This is consistent with obstructive lung dysfunction.

Reversibility is defined by an improvement in the FEV1 of $>12 \%$ and $>200 \mathrm{ml}$ and the FEV1 only improves $8 \%$ with a bronchodilator. There is an increase in the total lung capacity consistent with hyperinflation and a reduction in the diffusing limit for carbon monoxide (DLCO). Furthermore, there is a reduction in the vascular markings on the CT scan. These findings are all consistent with emphysema.

What is the most likely explanation for the patient's dyspnea?

1. Alpha-1 antitrypsin deficiency

2. She has likely been exposed to second-hand smoke

3. She is a "closet smoker" and has COPD

4. She likely has topamax-induced emphysema

5. None of the above 


\section{Correct! \\ 1. Alpha-1 antitrypsin deficiency}

The patient was diagnosed with alpha-1 antitrypsin (AAT-1) deficiency. Although there are reports of second-hand smoke causing lung disease, the presentation is classic for alpha-1 antitrypsin deficiency other than the patient is presenting somewhat later in life than usual. Topamax does not cause emphysema.

In AAT-1 deficiency circulating levels of AAT-1 are reduced due to an inherited deficiency usually seen in patients of Northern European origin. AAT-1 normally binds elastase released by neutrophils in the lung preventing tissue breakdown and emphysema. The obvious treatment is to replace circulating AAT-1 by infusion. However, when this was first proposed in the early 1980's it was dismissed as foolish and impractical. However, time has shown that AAT-1 replacement results in a reduction in the rate of decline of FEV1. However, the rate of decline varies between patients and AAT- 1 replacement is quite expensive (usually over $\$ 80,000 / y e a r$ ) and will not reverse severe emphysema. Lung transplant or lung volume reduction surgery can be performed on those with more severe emphysema.

Our patient had an AAT-1 level of $27.7 \mathrm{mg} / \mathrm{dL}$ (normal 150-350) and was phenotyped as $\mathrm{ZZ}$ rather than the normal MM. She is currently receiving alpha-1 replacement therapy and doing well.

\section{References}

1. American Thoracic Society, European Respiratory Society. American Thoracic Society/European Respiratory Society statement: standards for the diagnosis and management of individuals with alpha-1 antitrypsin deficiency. Am J Respir Crit Care Med. 2003;168:818-900. [CrossRef] [PubMed]

2. The Alpha-1-Antitrypsin Deficiency Registry Study Group. Survival and FEV1 decline in individuals with severe deficiency of alpha1-antitrypsin. Am J Respir Crit Care Med. 1998;158(1):49-59. [CrossRefl [PubMed]

3. Chapman KR, Burdon JG, Piitulainen E, et al. Intravenous augmentation treatment and lung density in severe $\alpha 1$ antitrypsin deficiency (RAPID): a randomised, doubleblind, placebo-controlled trial. Lancet. 2015;386(9991):360-8. [CrossRef] [PubMed] 